palate and flat nose), moderate (midface hypoplasia, hypotelorism), or mild (single central incisors, iris colobomas, anosmia). Feeding and swallowing difficulties are common. Microcephaly occurs in $75 \%$ of classic HPE cases, while one sixth require CSF shunting for hydrocephalus, especially in the alobar type and those with a dorsal cyst. Motor dysfunction varies and is most prevalent in the alobar and semilobar types of HPE. Outcome. This varies with the type and severity of HPE, and early mortality is expected in those with severe craniofacial or chromosomal abnormalities. Of 104 surviving cases evaluated at the Carter Centers, mean age was 4 years, and $15 \%$ were between 10 and 19 years of age. The recurrence risk of HPE is estimated at $6 \%$, and is highest in familial forms. A thorough family hstory is advised. Prenatal diagnosis attempted by ultrasound in $93 \%$ was positive in only $22 \%$ of cases. Fetal MRI may prove effective in characterizing the malformation in cases with positive ultrasound. (Hahn JS, Plawner LL. Evaluation and management of children with holoprosencephaly. Pediatr Neurol August 2004;31:79-88). (Respond: Jin S Hahn MD. Department of Neurology, A343, Stanford University School of Medicine, 300 Pasteur Drive, Stanford, CA 94305).

COMMENT. Holoprosencephaly is a congenital malformation caused by a defect in patterning of the basal forebrain in the first 4 weeks of embryogenesis, and characterized by incomplete separation of the cerebral hemispheres and basal ganglia. The mainly topographical classification of CNS malformations is being replaced by a classification based on integration of morphological and molecular genetic criteria (Sarnat and Sarnat, 2001; see Ped Neur Briefs 2001;15:57). The middle interhemispheric variant of HPE has previously been described as a distinct clinico-neuroradiologic subtype (Lewis et al, 2002; see Ped Neur Briefs Jan 2003;17:1-2). It differs from the lobar subtype by the absence of endocrine abnormalities and choreoathetosis. A delay in white matter maturation is described in 25 of 47 patients with HPE, a defect most evident in the MRI of infants and in severe subtypes (Barkovich et al, 2002; see Ped Neur Briefs Jan 2003;17:2-3).

\title{
FOCAL CORTICAL DYSPLASIA AND HOT WATER EPILEPSY
}

A 4-year-old girl with complex partial seizures triggered by bathing in hot water and found to have a left parietal focal cortical dysplasia on MRI is reported from the University of Siena, Italy. The interictal EEG showed spikes and spike-and-wave epileptiform discharges in the left parietal region. Spontaneous non-reflex complex partial seizures recurring at 3 months after the first HWE seizure at 6 months were resistant to carbamazepine and gabapentin and controlled by topiramate. This is the second patient with hot water epilepsy (HWE) rported in association with a cortical malformation. MRI is advised in patients with HWE. (Grosso S, Farnetani MA, Francione S, et al. Hot water epilepsy and focal malformation of the parietal cortex development. Brain Dev Sept 2004;26:490-493). (Paolo Balestri, Department of Pediatrics, University of Siena, Viale M Bracci, Le Scotte, 53100 Siena, Italy).

COMMENT. HWE accounts for $6.9 \%$ of all epilepsies in the Indian community, it is also common in Turkey but rare in other ethnic groups. Children are affected more frequently than adults. First reported in an Australian patient (Lenoir et al, 1989), HWE is classified as a benign reflex epilepsy with a good prognosis, usually occurring when hot water is poured on 
the head, but in response to immersion in hot water in $10 \%$ of cases. Spontaneous non-reflex complex partial seizures may occur later.

\section{PAROXYSMAL DISORDERS}

\section{EVALUATION OF SYNCOPE IN AN EMERGENCY DEPARTMENT}

The cause of syncope and diagnostic workup of 226 consecutive pediatric patients presenting at the emergency department were evaluated at the University of Liege, Belgium. Among 226 patients with the primary complaint of syncope, 144 were discharged and 82 were admitted to the hospital for further study. Neurocardiogenic syncope (NCS) was diagnosed in $181(80 \%)$, and neurologic disorders in $21(9 \%)$ included seizures in 18, viral meningitis in 1, narcolepsy (1), and stroke (1). Other causes included psychogenic in 8, cardiac in 5, breath-holding spells (4), intoxications (4), and hypoglycemia (1). Recurrences occurred in the psychogenic and cardiac groups. NCS was related to prolonged upright posture $(\mathrm{p}=0.0001)$ and other predisposing factors such as heat, mild dehydration, menses, hyperventilation, cough, urination, etc. The lack of a trigger excluded NCS. Exercise-related syncope was usually cardiac $(\mathrm{p}=0.03)$. Post-recovery symptoms such as fatigue, weakness, headache, and nausea were not indicative of a specific category. A neurologic deficit such as prolonged lethargy and confusion post-recovery was typical of a convulsive seizure or other neurologic problem $(\mathrm{p}<0.001)$. An electrocardiogram $(\mathrm{ECG})$ in suspected cardiac cases was relevant in 3 with conduction disorders; ECG was not performed in $132(58 \%)$ patients with other syncopes. Most patients with suspected NCS had an EEG and 29\% were admitted to hospital. Ancillary tests such as EEG, CT of head, blood analyses, echocardiography, and 24hour Holter recording, performed in many cases as part of the general evaluation, were largely non-diagnostic. Psychiatric disorders (depression, anorexia nervosa, school phobia, hysteria) had occurred in 13 of 181 patients with NCS at follow-up. The history and physical alone will usually point to the diagnostic category and need for specific tests. (Massin MM, Bourguignont A, Coremans C, et al. Syncope in pediatric patients presenting to an emergency department. J Pediatr Aug 2004;145:223-228). (Reprints: Prof Martial Massin MD, Division of Pediatric Cardiology, CHR Citadelle (University of Liege), Boulevard du 12 e de Ligne, 1, B-4000 Liege, Belgium).

COMMENT. The history of the event is critical for determining a working diagnosis and management plan. Attention should be given to possible triggers, the duration of the episode, and the condition in the post-recovery phase. A goal-directed plan of work-up is essential to avoid multiple unnecessary tests and costly hospitalization. A similar conclusion was reached in a report of syncope cases experienced at the Royal Hospital for Sick Children, Glasgow, UK (McLeod KA, 2003; see Ped Neur Briefs May 2003;17:36-37). Patients with prolonged loss of consciousness, seizure, and post-ictal lethary and confusion should receive an EEG, but routine EEG for suspected syncope had a $<1$ in 300 positive yield in the Belgian report. ECG also had a low positive yield. Tilt-table testing is indicated in patients with recurrent episodes, and provides an early diagnosis of NCS, avoiding further tests (Strieper et al, 1994; see Ped Neur Briefs 2003;17:37). 